\title{
Drying the corn in a farm heat pump dryer with fluidized bed
}

\section{Rudobashta, S.P. ${ }^{a^{*}}$; Zueva, G.A. ${ }^{\text {b }}$ Dmitriev, V.M. ${ }^{\text {; }}$ Muravleva, E.A. ${ }^{\text {d }}$}

${ }^{a}$ Department of Heat Engineering, Hydraulics and Enterprises Energy Supply. Russian State Agrarian University - MAA after K. A. Timiryazev, Moscow, Russia

b Department of Higher and Applied Mathematics, Ivanovo State University of Chemistry and Technology, Ivanovo, Russia

${ }^{\mathrm{c}}$ Department of Life Safety, Tambov State Technical University, Tambov, Russia

${ }^{\mathrm{d}}$ Department of Heat Engineering, Hydraulics and Enterprises Energy Supply. Russian State Agrarian University - MAA after K. A. Timiryazev, Moscow, Russia

*E-mail of the corresponding author: rudobashta@mail.ru

\begin{abstract}
The possibility of using a heat pump as a part of on-farm drying plant is considered taking drying of corn grain as an example. The methodology for kinetic calculations of a drying plant with a batch fluidized bed for granular materials is developed. These calculations are based on the use of an analytical solution for the problem of mass conductivity and taking into account the time-related changes in drying agent parameters over the layer height. To determine the concentration dependence of the mass-conductivity coefficient, a zonal method has been used.
\end{abstract}

Keywords: heat pump; dryer; kinetic calculation. 


\section{Introduction}

To increase the efficiency of using a heat pump in a farm, it can be used for heating a farmhouse in winter, and for household needs in summer, for example, for drying seed grains. The drying of corn grains in a farm is discussed in the paper.The objectives of this work are: 1) analysis of the efficiency of using a heat pump in grain dryer, 2) developing an engineering method for the kinetic calculations of a periodically operating fluid bed dryer based on the analytical method of kinetic calculations, 3) obtaining the data on the mass conductivity of corn grains.

\section{Farm heat pump dryer (HPD)}

The moisture content of corn harvested from the field is in many cases higher than that required by storage conditions, so it is removed by thermal drying. For this purpose, a farmer heat pump plant with a fluidized bed of periodic operation can be used in a farm specializing in the production of seed-quality grains. A thermodynamic analysis was performed for the operation of such an installation in which the source of low-potential heat is the ground and the drying agent is atmospheric air heated by a heat pump to a temperature of $60^{\circ} \mathrm{C}$. The R600a was taken as the refrigerant and its thermodynamic parameters were taken from literature. ${ }^{[1]}$ As the result of analysis, it was found that 1 ) the energy conversion coefficient is $\Psi=2.98$; 2 ) the energy saving for heating the drying agent is $66.4 \%$ due to the use of the heat pump, 3) for a fluidized-bed HPD at drying corn with a mass load of $75 \mathrm{~kg}$, the total electric energy costs for the process (for heat pump and for air purge through the dryer) are $\sim 16 \mathrm{~kW}$, which is acceptable for operation of the dryer in the farm. Thus, the performed analysis and calculations show using HPD for drying corn seeds on a farm is fully justified.

\section{Kinetic calculation of a batch fluidized bed dryer (FBD)}

The level of development the theory of drying, the mathematical modeling methods, the availability of effective computational programs, the widespread distribution of personal computers allow to use successfully the mathematical methods for the kinetic calculations of dryers - analytical ${ }^{[2,3]}$ and numerical ones. ${ }^{[4,5]}$ Such methods of kinetic calculations of continuous dryers for disperse materials has been developed. The operation of a batch dryer differs by the nonstationarity of the process, and it must be taken into account in the design calculation. In this paper, we present a method that takes into account the nonstationarity of the process. At the development stage the general kinetic problem was decomposed into two levels: microkinetic and macrokinetic. At the microkinetic level, the drying kinetics of single corn kernels were considered, and the influence of technological factors on the process was taken into account at the macrokinetic level. When formulating the microkinetic model, it was assumed that the grain is isotropic and assumes a shape of a 
sphere with a radius $\mathrm{R}$ which volume is equal to the grain volume. The zonal method of calculation was used: the entire range of the moisture content of the material during the drying process was divided into a number of concentration zones, for each of which was given the necessary values of the mass conductivity coefficient and of other characteristics of the process. The drying duration in these zones was calculated by the analytical solution of the mass-conductivity problem in a regular mode ${ }^{[6]}$

$$
\tau_{\mathrm{i}}=\frac{\mathrm{R}^{2}}{\mu_{\mathrm{i}}{ }^{2} \cdot \mathrm{k}_{\mathrm{i}}} \cdot \ln \frac{\mathrm{B}_{\mathrm{i}}}{\mathrm{E}_{\mathrm{i}}},
$$

where $\mu_{\mathrm{i}}$ is the first positive root of the characteristic equation for the solution of the problem at the i-th zone ${ }^{[6]} ; \bar{E}=\left(\bar{u}(\tau)-u_{e}\right) /\left(\bar{u}_{i n}-u_{e}\right)$ represents the relative average volume moisture content of the grains; $\overline{\mathrm{u}}$ - average moisture content of grain, $\mathrm{kgkg}^{-1}$; $\mathrm{B}_{\mathrm{i}}$ is the first preexponential factor of the solution of the mass-conductivity problem ${ }^{[6]}$. The grain temperature was calculated on the basis of the solution of the heat conduction problem. ${ }^{[6]}$ This solution for the medium-volume temperature of a spherical body has the form ${ }^{[6]}$

$$
\begin{aligned}
& \bar{\Theta}=\frac{\bar{t}(\tau)-t_{a}}{t_{i n}-t_{a}}=\sum_{n=1}^{\infty} B_{n}\left[\exp \left(-\mu_{n}^{2} F o\right)+\frac{R_{V}}{R} \operatorname{KoLu} \frac{\mu_{n}^{2}}{B i} \times\right. \\
& \left.\times \sum_{m=1}^{\infty} B_{m} \frac{\mu_{m}^{2}}{\mu_{m}^{2}-L u \cdot \mu_{m}^{2}}\left[\exp \left(-\mu_{m}^{2} F o \cdot L u\right)-\exp \left(-\mu_{n}^{2} \cdot \text { Fo }\right)\right]\right],
\end{aligned}
$$

where $\overline{\mathrm{t}}$ - average temperature of grain, ${ }^{\circ} \mathrm{C} ; \mathrm{B}_{\mathrm{n}}$ are coefficients that depend on the Biot number thermal; $R_{V}$ is the ratio of the volume of the body to its surface (for a sphere $R_{V}=$ 3); Fo - Fourier number caloric; Ko - Kossovitch number; Lu - Luikov number.

In describing the process at the macrokinetic level, it was assumed that in the FBD of a batch action, the solid phase is completely mixed, and the gas phase is ideally displaced. The moisture content and temperature of the drying agent in such a dryer vary both over layer height and in time. The kinetic calculation was carried out by the zonal method based on the average values of the air parameters in the concentration zones $\left(u_{i n . i} \ldots u_{f . i}\right)$, which were found from the equations of material and heat balance. To take into account changes in air parameters over time, the successive approximations method was applied: first, the drying time $\tau_{\mathrm{i}}$ required to change the moisture content of the material from $\mathrm{u}_{\mathrm{in} \cdot \mathrm{i}}$ to $\mathrm{u}_{\mathrm{f} . \mathrm{i}}$ was set, and then it was determined by calculation using equation (1). At the macrokinetic level, the following basic values were calculated: 1) the rate of fluidization beginning, at which the working air velocity was selected, and then the mass air flow in the 
dryer $\left(\mathrm{kgs}^{-1}\right.$ ) was determined; 2 ) the average in time $\tau_{\mathrm{i}}$ moisture content of the air at the outlet from the dryer $\bar{d}_{\mathrm{fi}}$ and then the average moisture content of the air in the layer on the time interval $\tau_{\mathrm{i}}: \overline{\mathrm{d}}_{\mathrm{la.i}} ; 3$ ) the average in time $\tau_{\mathrm{i}}$ temperature of the air at the outlet from the dryer $\bar{t}_{a . f . i}$, and then - the average air temperature in the layer. The average values of the temperature and air moisture content in the layer were used to find the mass coefficient and the equilibrium moisture content of the material in the zones.

\section{Experimental research. Materials and Methods}

The experiments were performed to determine the equivalent diameter, density, mass conductivity and hygroscopic properties of corn grain of the following three varieties currently cultivated in Russia: Pioneer PR-8521, Pioneer PR-7709 FAO 160, Mysodur Amelior F-70. Equivalent diameter was determined by measuring the volume of a group of grains using a graduated cylinder, density - by measuring the volume and their mass. For the Pioneer PR7709 FAO 160 corn, the following has been determined: $d_{\text {eq }}=8.24 \mathrm{~mm}, \rho=$ $1065 \mathrm{kgm}^{-3}$. The dependence $\mathrm{k}=\mathrm{f}(\mathrm{u}, \mathrm{t})$ was determined by the zonal method with the experimental drying curve taken in the absence of an external diffusion resistance. ${ }^{[6]}$ Drying curves were obtained for 10 corn kernels of the same equivalent diameter $\mathrm{d}_{\mathrm{eq}}=2 \mathrm{R}$ in a specially designed experimental setup with a triple replication of the tests, at five drying agent temperatures: $40,50,60,70$ and $80{ }^{\circ} \mathrm{C}$, at air velocity $5 \mathrm{~ms}^{-1}$. There is no external diffusion resistance at this air flow (its absence was judged by the fact that the change in the air velocity by half did not affect the drying curve). Corn grains were placed between the coils of the spring suspension, which was blown by the air stream in the transverse direction. The weight of the samples during drying was measured using the Techniport torsion balance PRLT with accuracy of $1 \mathrm{mg}$ without removing grains from the drying chamber. The data obtained in the experiment on the coefficient of mass conductivity are shown in Fig. 1 for corn Pioneer PR-8521 (for other varieties the dependencies are similar). The data analysis allowed to draw the following conclusions: 1) the dependence of $\mathrm{k}$ on $\mathrm{u}$ for different varieties of corn is of the same character, the values of the mass coefficient for different varieties are close in magnitude; 2) the mass conductivity coefficient changes significantly with the moisture content of the material, it requires to take this change into account when drying; 3 ) the functions $k=f(u, t)$ have the form characteristic for the seeds of other crops - such as canola, wheat, rye, barley, but greater in their values; 4) the rate of drying is limited by internal mass transfer. 


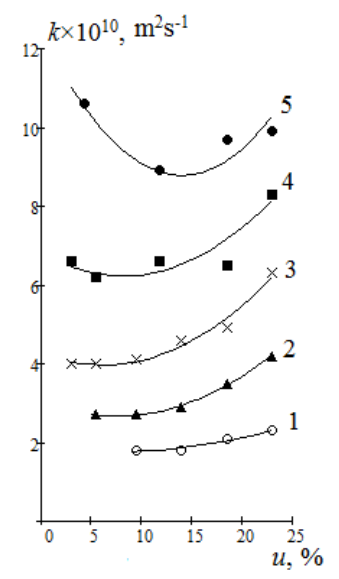

Fig. 1 Dependencies $\mathrm{k}=\mathrm{f}(\mathrm{u})$ for corn kernels of Pioneer PR-8521: $1-\mathrm{ta}_{\mathrm{a}}=40^{\circ} \mathrm{C} ; 2-50^{\circ} \mathrm{C}$; $3-60^{\circ} \mathrm{C} ; 4-70^{\circ} \mathrm{C} ; 5-\mathrm{t}_{\mathrm{a}}=80^{\circ} \mathrm{C}$ (points - experiment, lines - calculation).

\section{Verifying the adequacy of the mathematical model}

The adequacy of the model describing the microkinetic has been verified by comparing the experimental curve for drying the corn kernels located in a longitudinally blown monolayerat a low air velocity $\left(1.8 \mathrm{~ms}^{-1}\right)$ and the drying curve calculated for these conditions using the obtained data (note that the values of the mass coefficient were found from the drying curves, with an other air velocity $\sim 5 \mathrm{~ms}^{-1}$ ). Figure 2 allowes to compare the experimental and calculated drying curves, and it shows satisfactory match. The adequacy of the mathematical model describing the kinetics of corn grain drying in a batch fluidized bed

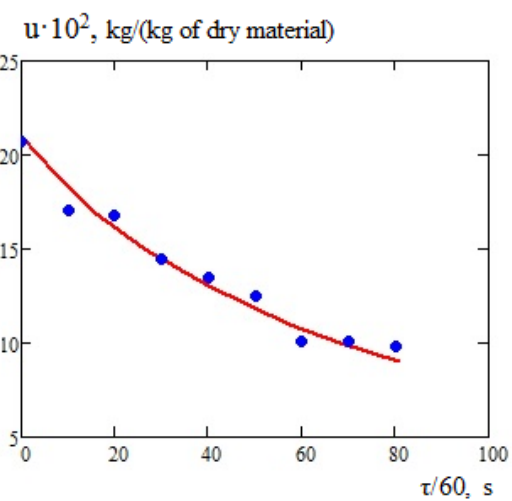

Fig. 2 Comparison of calculated (line) and experimental (points) drying curves for corn kernels of variety Pioneer PR-7709 FAO-16 $\left(\mathrm{t}_{\mathrm{a}}=50^{\circ} \mathrm{C}, \mathrm{v}=1.8 \mathrm{~ms}^{-1}\right)$. 
dryer has also been verified by comparison of the calculated and experimental drying curves, the latter being obtained under laboratory conditions. The scheme of the laboratory dryer is shown in Fig. 3. In the experiment, a curve was obtained for drying corn grain in a layer (dryer diameter $150 \mathrm{~mm}$, fixed bed height $190 \mathrm{~mm}$ ), measuring the air velocity, temperature and moisture content of the air at the entrance to the material layer and at the outlet from it. Fig. 4 showes the comparison of the calculated and experimental drying

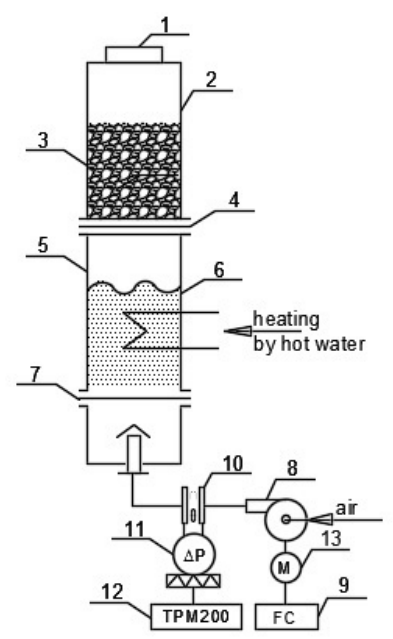

Fig. 3 Scheme of laboratory installation: 1 - air temperature meter; 2 - drying chamber; 3 - corn; 4, 7 - gas distribution grids; 5 - air heating chamber; 6 - glass balls; 8 - gas blower; 9 - frequency converter, 10 - measuring diaphragm; 11 - pressure transmitter, 12 - secondary device, 13 - motor.

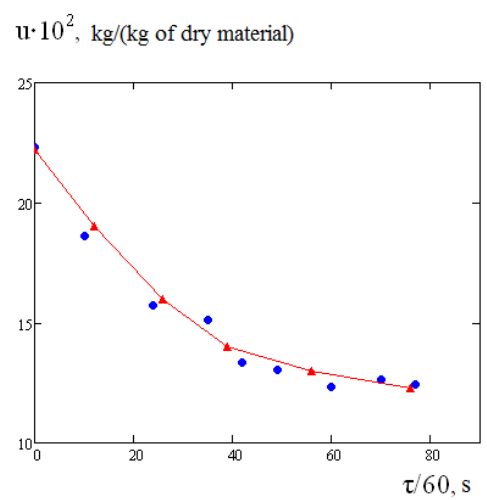

Fig. 4 Drying curves for grain variety PIONEERE PR-7709 FAO-16 in a batch fluidized bed dryer $\left(\mathrm{t}_{\mathrm{a} . \mathrm{in}}=53^{\circ} \mathrm{C} ; \mathrm{v}=2.3 \mathrm{~ms}^{-1}\right)$. 
curves whereas Fig. 5 presents the comparison of calculated and experimental air temperatures at the outlet from the layer of drying material. As can be seen, the experimental data compare well with the calculated ones.

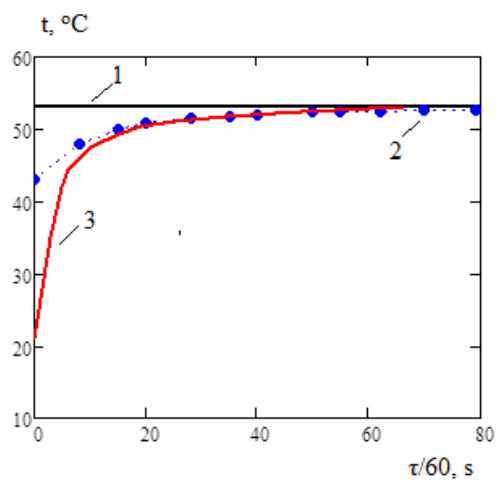

Fig. 5 Air temperature at the entrance to the material layer $t_{\text {a.in }}$ (1) and at the outlet from the layer $t_{a . f}:(2$ - experiment, 3-calculations).

\section{Conclusions}

1) The feasibility of using HPD in a farmer dryer for corn seed is shown. 2) A zonal analytical method for engineering calculation of a periodically operating dryers with a fluidized bed of particulate material is developed. 3) Data on corn kernels required for calculations are obtained. 4) There is an internal diffusion kinetic regime when drying corn. 5) The adequacy of the mathematical model for drying kinetics to the real process is shown.

\section{Nomenclature}

a

C

$\mathrm{k}$

$\lambda$

r

$r^{*}$

$\mathrm{R}$

$\mathrm{t}$

$\mathrm{u}$ thermal diffusivity

mass heat capacity

coefficient of mass

conductivity

thermal conductivity

coeffcient

radial coordinate

heat of vaporization

radius of spherical particle

temperature

moisture content of grain

$$
\begin{aligned}
& \mathrm{m}^{2} \mathrm{~s}^{-1} \\
& \mathrm{Jkg}^{-1} \mathrm{~K}^{-1} \\
& \mathrm{~m}^{2} \mathrm{~s}^{-1}
\end{aligned}
$$

$\mathrm{Wm}^{-1} \mathrm{~K}^{-1}$

m

$\mathrm{Jkg}^{-1}$

m

${ }^{\circ} \mathrm{C}$

$\operatorname{kgkg}^{-1}$ 
$\mathrm{v} \quad$ velocity of air $\mathrm{ms}^{-1}$

Greek letters

$\begin{array}{lll}\alpha & \text { heat transfer } & \\ & \text { coefficient } & \mathrm{Wm}^{-2} \mathrm{~K} \\ \rho & \text { grain density } & \mathrm{kgm}^{-3} \\ \tau & \text { time } & \mathrm{s}\end{array}$

Subscripts

$\begin{array}{ll}\text { a } & \text { air } \\ \text { e } & \text { equilibrium } \\ \mathrm{f} & \text { finite } \\ \text { in } & \text { initial } \\ \text { la } & \text { layer }\end{array}$

Dimensionless numbers

$$
\begin{aligned}
& \mathrm{Bi}=\alpha \mathrm{R} / \lambda-\text { Biot number } \\
& \mathrm{Fo}=\mathrm{a} \tau / \mathrm{R}^{2} \text { - Fourie number } \\
& \mathrm{Lu}=\mathrm{k} / \mathrm{a}-\text { Luikov number } \\
& \mathrm{Ko}=\mathrm{r}^{*}\left(\mathrm{u}_{\mathrm{in}}-\mathrm{u}_{\mathrm{e}}\right) /\left(\mathrm{c}\left(\mathrm{t}_{\mathrm{a}}-\mathrm{t}_{\mathrm{i}}\right)\right)-\text { Kossovitch number }
\end{aligned}
$$

\section{References}

[1] Alves-Filho, O. Heat Pump Drying: Theory, Design and Industrial Application; New Dry Tech: Trondheim, 2013.

[2] Rudobashta, S.; Zueva, G. Drying of seeds through oscillating infrared heating. Drying Technology, 2016, 34. (5), 505-515.

[3] Rudobashta S. P.; Zueva G. A.; Kartashov E. M. Heat and mass transfer when drying a spherical particle in an oscillating electromagnetic field. Theoretical Foundations of Chemical Engineering, 2016, 50 (5), 718-729.

[4] Bon J.; Kudra T. Enthalpy-Driven Optimization of Intermittent Drying. Drying Technology, 2007, 25 (4), 523 - 532.

[5] Vaquiro H. A.; Clemente G.; Garcia-Perez J. V.; Mulet A.; Bonb J. Enthalpy-driven optimization of intermittent drying of Mangifera indica L. Chemical Engineering Research and Design. 2009, 87, 885-898.

[6] Rudobashta, S.P. Mass Transfer in the Solid Phase Systems; Chemistry: Moscow, 1980 (in Russian). 